\title{
幽 \\ VIRTUALIDADES DA INFORMAÇÃO AMBIENTAL NO CONTEXTO DOS COMITÊS DE BACIAS HIDROGRÁFICAS DO RIO GRANDE DO SUL, BRASIL ${ }^{1}$
VIRTUALITIES OF THE ENVIRONMENTAL INFORMATION IN THE CONTEXT OF THE HYDROGRAPHIC BASIN COMMITTEES IN RIO GRANDE DO SUL, BRAZIL \\ VIRTUALIDADES DE LA INFORMACIÓN AMBIENTAL EN EL CONTEXTO DE LOS COMITES DE BACIAS HIDROGRÁFICAS DEL RÍO GRANDE DEL SUR, BRASIL
}

\author{
Luciana Turatti* \\ Jane Márcia Mazzarino**
}

\begin{abstract}
Resumo: $\mathrm{O}$ avanço dos meios de comunicação abre perspectiva para a participação cidadã e para o pleno exercício do direito à informação. Tal prerrogativa, contudo, depende da implementação das premissas legais relativas a tal direito expressas na Constituição Federal de 1988 e nas leis que a seguiram. A internet possibilita aos Comitês de Bacias Hidrográficas serem protagonistas da consecução do direito à informação, de modo a estimular a participação cidadã no debate público sobre a questão hídrica. Este estudo analisa a informação hídrica veiculada pelos comitês de bacias hidrográficas do RS no ambiente virtual, a fim de discutir de que modo suas práticas comunicativas atendem aos pressupostos legais do direito à informação. O estudo é descritivo e analítico, quanti-qualitativo, de base bibliográfica e documental. A amostra incluiu 25 comitês de bacias hidrográficas do Rio Grande do Sul, onde foram analisadas três categorias: acesso, informação ofertada e redes sociais.
\end{abstract}

Palavras-chave: Direito à informação; Comitês de bacias hidrográficas; Ambiente virtual.

\begin{abstract}
The advancement of the media opens the perspective for citizen participation and the full exercise of the right to information. This prerogative, however, depends on the implementation of legal premisses regarding such rights expressed in the 1988 Federal Constitution and the laws that followed. The internet allow the Hydrographic Basin Committees to be the protagonists of the implementation of the right to information, in order to encourage the citizen participation in public debate on the water issue. This study analyzes the information provided about water by the river basin committees of the RS in the virtual media, in order to discuss how their communication practices fulfill the legal requirements of the right to
\end{abstract}

\footnotetext{
1 Este estudo é resultado de pesquisa apoiada pelo Conselho Nacional de Desenvolvimento Científico e Tecnológico CNPq e pela Fundação de Amparo à Pesquisa do Estado do Rio Grande do Sul - FAPERGS.

"Professora do curso de direito e dos Programas de Pós-Graduação Stricto Sensu em Ambiente e Desenvolvimento (PPGAD) e do Programa em Sistemas Ambientais Sustentáveis (PPGSAS). E-mail: lucianat@ univates.br. ORCID iD: http://orcid.org/0000-0002-6684-1422

** Professora do curso de comunicação e do Programas de Pós-Graduação Stricto Sensu em Ambiente e Desenvolvimento (PPGAD). E-mail: janemazzarino@ univates.br. ORCID iD: https://orcid.org/0000-0002-6051-5116
} 
information. The study is descriptive and analytical, quantitative and qualitative, with bibliographic and documental base. The sample included 25 river basin committees of Rio Grande do Sul, where three categories were analyzed: access, offered information and social networks.

Key-words: Right to information; River basins committees; Virtual media.

Resumen: El avance de los medios de comunicación abre la perspectiva para la participación ciudadana y para el pleno ejercicio del derecho a la información. Tal prerrogativa, sin embargo, depende de la aplicación de las premisas legales relativas a tal derecho expresadas en la Constitución Federal de 1988 y en las leyes que la siguieron. La Internet permite a los Comités de Cuencas Hidrográficas ser protagonistas de la consecución del derecho a la información, para estimular la participación ciudadana en el debate público sobre la cuestión hídrica. Este estudio analiza la información hídrica vehiculada por los comités de cuencas hidrográficas del RS en el ambiente virtual, a fin de discutir de qué modo sus prácticas comunicativas atiende a los presupuestos legales del derecho a la información. El estudio es descriptivo y analítico, cuantitativo, de base bibliográfica y documental. La muestra incluyó 25 comités de cuencas hidrográficas de Rio Grande do Sul, donde se analizaron tres categorías: acceso, información ofrecida y redes sociales.

Palabras-clave: Derecho a la información; Comités de cuencas hidrográficas; Entorno virtual.

\section{Introdução}

É pacífico o entendimento de que o acesso à informação sobre questões ambientais contribui para o desenvolvimento sustentável e para a efetiva participação pública nos processos de governança ambiental. No entanto, apesar da disseminação do conhecimento acerca dos instrumentos que vem tentando assegurar tal direito ao longo das últimas décadas, percebe-se que no cotidiano dos órgãos públicos tal prerrogativa ainda carece de efetivação.

O reconhecimento do direito à informação no plano nacional foi plenamente assegurado com a promulgação da Constituição Federal de 1988, a qual internalizou expressamente tal preceito na condição de direito fundamental (BRASIL, [2019]). No contexto ambiental não foi diferente, posto que, vários documentos, de caráter internacional e nacional impõem o dever de informar aos órgãos ambientais, entre os quais incluem-se os Comitês de Bacia Hidrográfica.

Este artigo analisa como os 25 Comitês de Bacia Hidrográfica do Rio Grande do Sul RS têm se valido de tais prerrogativas para informar à população por meio do ambiente virtual, a fim de discutir de que modo suas práticas comunicativas atendem aos pressupostos legais do direito à informação. A escolha por estes canais se deve à facilidade de acesso ao meio por parte dos pesquisadores, sem que se ignore a existência de outras formas de divulgação das informações por ele produzidas como rádio, jornais e outros. E, também, por estar previsto na legislação seu uso. 
Para tanto, num primeiro momento, discorre-se acerca dos instrumentos legais internacionais e nacionais que preveem o direito/dever de informar, posto que, aos comitês, na condição de representantes dos usuários da água, e de parlamento da água, incumbe o dever de observar tais normativas. Segue-se a apresentação do método e na sequência são apresentadas as análises e a discussão dos resultados.

\title{
2 A Informação Ambiental como Direito
}

Em 1992, quando da elaboração da Declaração do Rio, durante a Conferência das Nações Unidas sobre Meio Ambiente e Desenvolvimento, conhecida como Eco 92, os países presentes no evento estabeleceram no princípio 10 da referida Declaração que:

\begin{abstract}
A melhor maneira de tratar as questões ambientais é assegurar a participação, no nível apropriado, de todos os cidadãos interessados. No nível nacional, cada indivíduo terá acesso adequado às informações relativas ao meio ambiente de que disponham as autoridades públicas, inclusive informações acerca de materiais e atividades perigosas em suas comunidades, bem como a oportunidade de participar dos processos decisórios. Os Estados irão facilitar e estimular a conscientização e a participação popular, colocando as informações à disposição de todos (ORGANIZAÇÃO DAS NAÇÕES UNIDAS, 1992).
\end{abstract}

Como forma de dar consecução a tal propósito, no ano de $1998^{2}$, vários países europeus no âmbito da Comissão Econômica para a Europa da Organização das Nações Unidas (ONU), adotaram a Convenção de Aarhus, sobre "Acesso à Informação, à Participação Pública nos Processos Decisórios e ao Acesso à Justiça em Matéria Ambiental". A convenção entrou em vigor em janeiro de 2001.

Apesar desta não ser aplicada ao Brasil, ela serve de referencial ético para o estabelecimento de formas de cooperação internacional que se voltem para a proteção do meio ambiente, posto que se propõe a assegurar a todos os cidadãos o acesso à informação e, em especial, a participação na tomada de decisões, pois demonstra preocupação não somente no sentido de se assegurar o acesso aos documentos em poder dos órgãos públicos, mas também impõe ao Poder público o dever de disseminar as informações. Nesse contexto, o Estado assume a incumbência de organizar, processar e manter atualizadas as informações, sob pena de, no contrário, macular a participação da sociedade e limitar o exercício da cidadania.

A Convenção também se faz importante por definir o que vem a ser a informação ambiental. Segundo seu texto, art. $2^{\circ}$, item 3 , trata-se de qualquer informação apresentada sob a forma escrita, visual, oral, eletrônica ou outra sobre:

2 Por ocasião da IV Conferência Ministerial "Ambiente para a Europa". 
a) o estado de elementos do ambiente, tais como o ar e a atmosfera, a água, o solo, a terra, os locais de interesse paisagístico e natural, a diversidade biológica e os seus componentes, incluindo os organismos geneticamente modificados e a interacção entre estes elementos;

b) factores, tais como substâncias, energia, ruído e radiação e actividades ou medidas, incluindo medidas administrativas, acordos em matéria de ambiente, políticas, legislação, planos e programas que afectem ou que sejam susceptíveis de afectar os elementos do ambiente referidos na alínea "a", bem como análises custo-benefício e outras análises económicas e pressupostos utilizados no processo de tomada de decisões em matéria ambiental;

c) o estado da saúde humana e da segurança, as condições de vida dos indivíduos, os locais de interesse cultural e as estruturas construídas, na medida em que estes elementos sejam ou possam ser afectados pelo estado dos elementos do ambiente ou, através desses elementos, pelos factores, actividades ou medidas referidas na alínea "b" (COMISSÃO ECONÓMICA DAS NAÇÕES UNIDAS PARA A EUROPA, 2003, p. 9-10).

O conceito apresentado, apesar de abrangente, é capaz de fixar para o Poder Público os contornos e limites do dever de informar na área ambiental. No cenário brasileiro, em 2003 publica-se a Lei 10.650, a qual dispõe sobre o acesso público aos dados e informações existentes nos órgãos e entidades integrantes do Sistema Nacional de Meio Ambiente - SISNAMA. (BRASIL, 2003).

Em seu artigo $2^{\circ}$, a lei prevê que os órgãos e entidades da Administração Pública, direta, indireta e fundacional, integrantes do SISNAMA, ficam obrigados a permitir o acesso público aos documentos, expedientes e processos administrativos que tratem de matéria ambiental e a fornecer todas as informações ambientais que estejam sob sua guarda, em meio escrito, visual, sonoro ou eletrônico, estabelecendo o prazo de 30 dias para manifestação do órgão público (BRASIL, 2003). Conforme se constata, a lei não coloca o acesso à informação como uma possibilidade, mas sim como uma obrigação dos órgãos ambientais.

Reforçando a política de acesso à informação, em 18 de novembro de 2011, é publicada a Lei $12.527^{3}$ que regula o acesso a informações previsto no inciso XXXIII do art. 5ำ no inciso II do $\S 3$ o do art. 37 e no $\S 2^{\circ}$ do art. 216 da Constituição Federal, prevendo os procedimentos que devem ser observados pelos órgãos e entidades do poder público como forma de assegurar tal direito (BRASIL, 2011).

Esta lei realiza um resgate dos fins e princípios republicanos, haja vista que, se devidamente aplicada, ela é capaz de assegurar maior transparência aos processos públicos e, por consequência, envolver os cidadãos quando das deliberações acerca das políticas públicas. Ao longo do seu texto, mais especificamente no artigo $6^{\circ}$, I, a lei prevê que cabe aos órgãos e entidades do poder público, assegurar a gestão transparente da informação, propiciando amplo

3 A lei foi regulamentada por meio do Decreto Federal 7.724 de 2012, o qual estabelece os procedimentos para a garantia do acesso à informação e para a classificação de informações sob restrição de acesso, observados grau e prazo de sigilo. (BRASIL, 2011) 
acesso a ela e sua divulgação. Em vista disso, é tarefa do Poder Público identificar os mecanismos que alcançam os mais diversos grupos sociais de forma a dar eficácia a este artigo.

Em outra passagem de seu texto, a lei refere que os procedimentos nela previstos, voltados para a efetivação do direito fundamental de acesso à informação, devem ser executados com a observância de algumas diretrizes, entre as quais destacam-se: I - observância da publicidade como preceito geral e do sigilo como exceção; II - divulgação de informações de interesse público, independentemente de solicitações.

Ou seja, a regra ora vigente aponta no sentido de que as informações devem ser publicizadas, independentemente de requerimentos dos cidadãos e a exceção são as situações envolvendo sigilo, como ainda ocorre com os casos envolvendo a segurança nacional. Além disso, a divulgação deve ser realizada em locais de fácil acesso (art. $8^{\circ}$ ), produzidas pelo próprio órgão ou por ele custodiada.

Acerca desta última determinação, há de se ter presente que isto implica o dever de difundir informações preferencialmente chanceladas por órgãos públicos ou instituições e organismos de credibilidade, preterindo-se, por consequência, notícias e outras informações de fontes não fidedignas, já que tais informações devem se propor a assegurar a formação do pensamento seguro por parte dos cidadãos dispostos a participar dos processos de deliberação.

Os comitês de bacias, por serem considerados órgãos de Estado devem cumprir tais obrigações, devendo ter presente que a simples divulgação de informações, oriundas, por exemplo, da mídia de massa, coloca os comitês na condição de meros transmissores, que legitimam a mídia sem discuti-la ou aproximá-la das realidades locais, desconsiderando o fato de que é em âmbito local que serão desencadeadas as principais ações dos cidadãos.

Como forma de atender as prerrogativas impostas pela lei, a legislação prevê o uso da internet. No parágrafo segundo do artigo $8^{\circ}$, estabelece que os órgãos e entidades públicas deverão utilizar todos os meios e instrumentos legítimos de que dispuserem, sendo obrigatória a divulgação em sítios oficiais da rede mundial de computadores (internet).

Tal proposta se aproxima em muito das atuais formas de gestão, onde o uso das Tecnologias da Informação, denominada de Governo Eletrônico tem como fim "regenerar e aperfeiçoar os serviços prestados à população e estimular a interação e discussão dos problemas locais", ampliando ainda mais a transparência dos processos públicos (CAVALCANTI; DAMASCENO; SOUZA NETO, 2013, p. 113).

O acesso prévio à informação é capaz de diminuir o número de consultas junto aos órgãos públicos por parte dos cidadãos, gerando, por consequência, economia de tempo e recursos para administração, além de assegurar que o cidadão, quando do chamamento para a participação em processos decisórios, esteja munido das informações necessárias para poder participar de processos deliberativos. 
Ao estabelecer a obrigatoriedade de divulgação das informações ambientais o Art. $2^{\circ}$ da Lei 10.650 prevê os temas que entendeu de maior relevância e, portanto, prioritários quando da escolha das pautas de divulgação. São eles:

I - qualidade do meio ambiente; II - políticas, planos e programas potencialmente causadores de impacto ambiental; III - resultados de monitoramento e auditoria nos sistemas de controle de poluição e de atividades potencialmente poluidoras, bem como de planos e ações de recuperação de áreas degradadas; IV - acidentes, situações de risco ou de emergência ambientais; V - emissões de efluentes líquidos e gasosos, e produção de resíduos sólidos; VI - substâncias tóxicas e perigosas; VII - diversidade biológica; VIII - organismos geneticamente modificados. (BRASIL, 2003)

Tal lista não é taxativa, cabendo ainda ao agente público deliberar acerca dos demais assuntos a serem divulgados, com base no propósito de permitir a participação cidadã.

O que é certo, como diz Dowbor, é que a situação é paradoxal, pois, nunca se teve acesso a tanta tecnologia de informação como hoje, e também, nunca houve tamanha confusão. "Bancos de dados, redes, portais, sites, conferências online, educação à distância, grupos de discussão, conexões de banda larga, geoprocessamento, sensoriamento remoto, generalização de acesso à telefonia, - tudo indica uma autêntica explosão de capacidades técnicas de levantamento, organização e distribuição da informação.” (DOWBOR, 2003, p. 3). Os propósitos do Estado e dos entes públicos devem, portanto, se voltar para a organização da informação a partir das realidades locais e das necessidades práticas dos atores sociais como forma de permitir a ampliação da democracia participativa e a superação do paradigma do silêncio adotado pelo Estado ao longo do último século (GERALDES; REIS, 2012).

Geraldes e Reis (2012) tecem uma crítica ao Estado brasileiro, ao afirmar que este não desenvolveu o hábito de produzir e compartilhar informações com toda sociedade porque historicamente, culturalmente, ele dialoga com um grupo da sociedade, com uma classe que usa da informação exclusiva como um privilégio a mais. Saber de uma ação do Estado com antecedência pode significar acesso a recursos, sair na frente em uma corrida cujos vencedores já estão, de antemão, definidos.

Como referem Sarlet e Fensterseifer (2018, p. 443) o acesso à informação se coloca como um potente "mecanismo de equalização das relações jurídicas" ao passo que permite ao cidadão, seja de forma individual ou coletiva "reivindicar, em um patamar mais igualitário, o respeito ao seu direito fundamental ao ambiente".

O papel de informar faz parte das funções do Estado, e não do mercado, mesmo que hoje, com a difusão das redes sociais a própria sociedade também esteja produzindo informações relevantes.

Há que se citar ainda que no plano supraestatal, em 04 de março de 2018, foi firmado por representantes da América Latina e Caribe, dentre os quais o Brasil, em San José da Costa Rica, 
um Acordo regional com caráter vinculante de suma importância para implementação do Princípio 10 da Declaração do Rio de Janeiro sobre o Meio Ambiente e o Desenvolvimento. O Acordo Regional sobre o Acesso a Informação, a Participação Pública e o Acesso a Justiça em Assuntos Ambientais na América Latina e Caribe, ou simplesmente, Acordo de Escazu, como ficou conhecido, tem o objetivo de proteger direitos de acesso à informação, à participação pública e à Justiça em temas ambientais.

Tendo presente a importância que tal direito atingiu na sociedade contemporânea, a qual tem feito uso ilimitado dos mecanismos virtuais de informação, e sabendo-se da necessidade de ampliação da transparência dos processos públicos, como forma de se permitir uma participação mais responsável dos cidadãos, questiona-se como os 25 Comitês de Bacias Hidrográficas do Rio Grande do Sul tem feito uso dos seus canais na internet, incluindo as redes sociais, para envolver a população na consecução dos seus propósitos de gerir um bem comum, os recursos hídricos, assegurando acesso igualitário?

\section{Método}

O estudo é exploratório, descritivo e analítico, quanti-qualitativo de base bibliográfica e documental. A amostra documental é não probabilística, por tipicidade e acessibilidade. Os documentos analisados são publicações nas mídias virtuais dos 25 Comitês de Bacias Hidrográficas do Rio Grande do Sul: Apuaê Inhandava, Alto Jacuí, Baixo Jacuí, Butuí - Icamaquã, Piratinim, Caí, Camaquã, Gravataí, Guaíba, Ibicuí, Ijuí, Lagoa Mirim São Gonçalo, Litoral Médio, Mampituba, Pardo, Passo Fundo, Rio Negro, Rio Várzea, Santa Maria, Sinos, Taquari-Antas, Tramandaí, Turvo (Santa Rosa Santo Cristo), Quaraí e Vacacaí.

A opção pelas páginas dos comitês na internet em detrimento de outros meios de comunicação justifica-se pelo aumento no número de acessos ao longo da última década, tendo esta ferramenta se transformado num dos principais canais de comunicação para com o grande público.

Iniciou-se com um estudo exploratório sobre informações ofertadas pelos 25 comitês gaúchos em 2013. Ao final desta etapa, eliminaram-se 14 dos comitês que não apresentavam páginas oficiais ou não realizaram atualizações periódicas ao longo do ano. Na segunda etapa de análise foram incluídos apenas os 11 comitês que apresentaram as atualizações periódicas.

Tendo-se definido o corpus da pesquisa, foram identificadas as ferramentas de comunicação disponíveis nas páginas da internet, utilizadas por estas organizações para a comunicação social. A partir daí realizaram-se as análises: primeiramente exploratórias, posteriormente, descritivas. 
As unidades foram agremiadas em categorias, que emergiram da identificação do conjunto de unidades organizadas por semelhança. Com base nelas construiu-se "a estrutura de compreensão e de explicação dos fenômenos investigados" (MORAES, 2007, p. 91).

Três categorias compõem as análises: Acesso (subcategorias: aspectos visuais e atualização); Informação (subcategorias: informações institucionais disponibilizadas, temas de notícias publicadas, imagens); Redes (subcategorias: uso e relacionamento nas redes sociais, integração com outros órgãos). As análises referem-se às duas etapas de coletas, por isso variam quanto a amostra de comitês incluídos em cada subcategoria.

Na próxima seção apresentam-se os resultados por categorias e suas subcategorias, com uso de quadros quando necessário para sua melhor compreensão. Em seguida, faz-se a discussão dos dados, com seu cruzamento com o referencial teórico.

\section{Análises}

\subsection{Categoria Acesso}

a) Visibilidade e acessibilidade do site

Esta análise foi realizada nos 19 comitês que mantêm site, atualizado ou não, sendo considerado atualizado o site dos comitês que promovessem atualizações periódicas ao longo do ano. Quanto à visibilidade encontraram-se três situações: ótima em 10 dos sites analisados, boa ou razoável em 8 e ruim em 1 site. Considerou-se visibilidade ótima quando a oferta de informações explorava a estética das imagens, ofertava mapas, dispunha de galeria de imagens, apresentava imagens em movimento, adequava imagens aos textos disponibilizados, utilizava diferentes tamanhos de fontes (título, textos, links) e explorava o contraste de cores no site.

Considerou-se como visibilidade boa ou razoável quando a oferta de imagens era inexistente ou, então, quando estas ocupavam grande parte da página, bem como quando o tamanho da fonte era considerado bom ou excessivamente grande, sem, contudo, explorar a diversidade, e ainda quando havia um contraste razoável entre as cores. Ruim foi considerado apenas um site por ofertar pouco conteúdo, péssimo contraste de cores dificultando inclusive a leitura, além de fonte pequena no texto. Portanto, 18 dos 19 sites analisados demonstraram preocupação estética ao implementar o direito à informação nos meios virtuais.

Quanto à acessibilidade 16 dos 19 sites foram considerados de boa acessibilidade por ofertarem conteúdos bem distribuídos, de modo a facilitar a visualização do internauta, bem como mapa dos links disponíveis. Foram considerados de acessibilidade ruim os sites com pouca informação, confusos, com dados de difícil visualização ou que forçavam um download para o acesso dos dados, com excesso de links que direcionavam a outras páginas (sem dispor o conteúdo na página do comitê), ou com links de acesso que não funcionavam, não redirecionando para outras páginas. 
b) Atualização do site e Facebook

Em relação ao site, dos 25 comitês analisados, 7 não informavam as datas de postagens, sendo que em um deles percebeu-se que a atualização era diária ou semanal. Oito dos 25 estavam desatualizados, sem postagens há mais de um mês no mínimo. Quatro haviam atualizado postagens no mês da coleta. E seis não tinham site, mas disponibilizavam informações junto ao site da Secretaria de Meio Ambiente ou da Fundação Estadual de Proteção Ambiental Henrique Luiz Roessler - RS (FEPAM).

Em relação ao Facebook, apenas 7 demonstraram utilizar esta ferramenta mantendo-a atualizada com postagens, com exceção do Comitê Taquari Antas, que tinha data da última postagem quatro meses antes da coleta de dados.

Apenas 3 atualizavam tanto o site como o Facebook: Ibicuí, Pardo e Passo Fundo. Seis atualizavam uma ou outra: Sinos, Vacacaí, Caí, Santa Maria e Tramandaí. E um não atualizava o facebook e o seu site estava há mais de um mês sem postagem, apesar de ser o único que mantinha assessoria de imprensa (Taquari-Antas). Acerca deste último ainda cabe ressaltar que a atualização dos dados ocorria apenas com o emprego de informações próprias, não valendo-se de postagens de outros sites, como os comitês que mais atualizam fazem.

Não atualizavam ou não dispunham de informações em nenhuma das duas ferramentas 16 comitês dos 25: Alto Jacuí, Baixo Jacuí, Apuaê Inhandava, Guaíba, Rio Negro, Rio Várzea, Litoral Médio, Gravataí, Turvo Santa Rosa Santo Cristo, Quaraí, Ijuí, Butuí-Icamaquã, Piratinim, Camaquã, Lagoa Mirim São Gonçalo e Mampituba. 
Quadro 1 - Atualização dos sites e rede social

\begin{tabular}{lc}
\hline \multicolumn{1}{c}{ Situação } & Comitê \\
\hline $\begin{array}{l}\text { Atualiza site } \\
\text { Atualiza Facebook }\end{array}$ & Ibicuí, Pardo, Passo Fundo \\
\hline $\begin{array}{l}\text { Atualiza site } \\
\text { Não tem Facebook }\end{array}$ & Sinos, Vacacaí \\
\hline $\begin{array}{l}\text { Não atualiza site } \\
\text { Atualiza Facebook }\end{array}$ & Caí, Santa Maria, Tramandaí \\
\hline $\begin{array}{l}\text { Atualiza pouco site } \\
\text { Não atualiza Facebook }\end{array}$ & $\begin{array}{c}\text { Taquari Antas } \\
\text { Não informava data de postagens do } \\
\text { site, mas demonstrava pouca } \\
\text { atualização OU } \\
\begin{array}{l}\text { Site com pouca atualização } \\
\text { Não tem Facebook }\end{array}\end{array}$ \\
\hline $\begin{array}{l}\text { Não atualiza site } \\
\text { Não tem Facebook }\end{array}$ & $\begin{array}{c}\text { Camaquã, Alto Jacuí, Baixo Jacuí, } \\
\text { Apuaê Inhandava, Guaíba, } \\
\text { Piratinim, Rio Negro, Rio Várzea, } \\
\text { Litoral Médio }\end{array}$ \\
\hline $\begin{array}{l}\text { Link da Secretaria de Meio Ambiente } \\
\text { ou da Fepam do RS direcionavam para } \\
\text { informações gerais sobre o Comitê e a } \\
\text { Bacia. }\end{array}$ & $\begin{array}{c}\text { Turvo, Santa Rosa, Santo Cristo, } \\
\text { Quaraí, Ijuí, Butuí-Icamaquã, }\end{array}$ \\
\hline
\end{tabular}

Fonte: as autoras.

O Quadro 1 demonstra que apenas 4 atualizavam o site e 7 o facebook ao longo de cada mês, o que aponta que a informação ao cidadão por meio de ferramentas da internet não é priorizada pelos demais. Isto num cenário onde os comitês trabalham com verba reduzida e a internet possibilita informar sem custos e limites geográficos, constituindo-se de um canal direto entre comitês e cidadãos, sem limite de acesso.

\subsection{Categoria Informação}

a) Informações institucionais

Em relação às informações institucionais disponibilizadas no site selecionaram-se os 11 comitês que apresentaram atualizações mais recentes para a análise. Observou-se três categorias de informações disponibilizadas: de perfil, relativas às atividades e técnicas.

As de perfil incluíam informações sobre o que é e como participar do comitê, regimento, histórico, fotografias, hino do comitê, endereço e contatos, nomes dos membros do comitê, depoimentos, parcerias, links pra organizações parceiras, notícias, entrevistas.

As atividades referem-se a agenda, datas de reuniões, atas, controle de frequência, ofícios e convocações, deliberações.

Enquanto as informações técnicas apresentam dados sobre legislação, plano de bacia, estudos sobre águas, artigos, dicas de educação ambiental, projetos, mapa da bacia, outorgas, tarifas e previsão do tempo. 
As informações mais frequentes eram sobre agenda, endereço, contatos, atas, datas de reuniões, depoimentos, regimento, parcerias e legislação, demonstrando com isso, que há uma mistura das 3 categorias.

No Facebook as postagens dos sete comitês que mantêm esta ferramenta caracterizam-se como mais superficiais e econômicas em relação ao site: Informam sobre suas atividades, informação jornalística ou técnica. Encontram-se postagens relativas às inscrições para participar do comitê, divulgação de eventos e cursos, mensagens, ações de gestão como construção do pacto das águas, campanhas, fotografias institucionais, participação em mídias comerciais, comemorações de aniversário do comitê, lançamento de publicação de atlas das águas da bacia, reuniões ordinárias e extraordinárias, técnicas, de eleição e audiências públicas.

b) Número de notícias publicadas e temas

Conforme se pode constatar no Quadro 2 abaixo, por ordem, Santa Maria, Pardo e Tramandaí são os que publicam a maior quantidade de conteúdo. Camaquã e Rio Negro são os que menos publicam. Os demais publicam medianamente.

Dos 25 comitês do RS, 14 não têm publicações periódicas nas mídias disponibilizadas na internet. Dos 11 que as utilizam, quatro comitês privilegiam o uso de website, quatro preferem facebook, um prefere o blog e dois não privilegiam o uso destas mídias na sua comunicação social. Portanto, dos 9 que privilegiam o uso destas mídias, todos fazem uso de uma delas predominantemente, e não de mais que uma. 
Quadro 2 - Número de notícias publicadas por Comitê nas diferentes mídias em 2013

\begin{tabular}{|c|c|c|c|c|c|c|}
\hline Comitê/Mídia & Site & Blog & Facebook & Twitter & Total & Observações \\
\hline Taquari Antas & 19 & 0 & 7 & 0 & 26 & Privilegia site \\
\hline Sinos & 19 & 0 & 0 & 0 & 19 & Privilegia site \\
\hline Tramandaí & 0 & 37 & 18 & 0 & 55 & $\begin{array}{c}\text { Privilegia blog, } \\
\text { repassando informações } \\
\text { de fontes diversas, } \\
\text { principalmente } \\
\text { midiáticas, sem produzi- } \\
\text { las }\end{array}$ \\
\hline Caí & 1 & 0 & 34 & 0 & 35 & Privilegia Facebook \\
\hline Camaquã & 6 & 0 & 0 & 0 & 6 & $\begin{array}{c}\text { Não privilegia estas } \\
\text { mídias }\end{array}$ \\
\hline Ibicuí & 12 & 0 & 28 & 0 & 40 & Privilegia Facebook \\
\hline Alto Jacuí & 23 & 0 & 0 & 0 & 23 & Privilegia site \\
\hline Pardo & 6 & 0 & 49 & 0 & 55 & Privilegia Facebook \\
\hline Passo Fundo & 18 & 0 & 4 & 0 & 22 & Privilegia site \\
\hline Rio Negro & 7 & 0 & 0 & 0 & 7 & $\begin{array}{c}\text { Não privilegia estas } \\
\text { mídias }\end{array}$ \\
\hline Santa Maria & 6 & 0 & 56 & 0 & 62 & Privilegia Facebook \\
\hline
\end{tabular}

Fonte: as autoras.

Já no quadro 3 é possível visualizar os principais temas das notícias publicadas.

Quadro 3 - Temas das notícias publicadas nos sites e no blog

\begin{tabular}{|c|c|c|c|}
\hline Comitê/Categoria & $\begin{array}{c}\text { Número } \\
\text { notícias } \\
\text { (site ou blog) } \\
\end{array}$ & Categoria Eventos & Categoria Divulgação \\
\hline Taquari Antas & 19 & $\begin{array}{c}7 \\
\text { Encontro, reunião }\end{array}$ & $\begin{array}{l}12 \\
\text { Audiência, plano de bacia, eleição, } \\
\text { comissão temática, estudo de cheias, } \\
\text { problema da suinocultura, energia, } \\
\text { aniversário do comitê, estudo }\end{array}$ \\
\hline Sinos & 19 & $\begin{array}{c}7 \\
\text { Reunião, plano de } \\
\text { bacia, seminário, } \\
\text { celebração, festa, } \\
\text { semana meio } \\
\text { ambiente }\end{array}$ & $\begin{array}{c}12 \\
\text { Enquadramento das águas, cheias, } \\
\text { estudo, escassez, boatos, inscrições, } \\
\text { plano de bacia, revistas e livros, } \\
\text { barragem, projeto }\end{array}$ \\
\hline $\begin{array}{l}\text { Tramandaí } \\
\text { (blog) }\end{array}$ & 37 & $\begin{array}{c}7 \\
\text { Reunião, fórum, } \\
\text { exposição, oficina }\end{array}$ & $\begin{array}{c}30 \\
\text { Convênio, lazer, saneamento, rio, } \\
\text { termo de conduta, crimes, } \\
\text { despoluição, corrupção, } \\
\text { recuperação, monitoramento, } \\
\text { legislação, licenciamento, estação } \\
\text { de investimentos, eleições, } \\
\text { entrevistas, energia, projetos, } \\
\text { decisão, órgão públicos, carta de } \\
\text { evento }\end{array}$ \\
\hline Caí & 1 & & 1 \\
\hline
\end{tabular}




\begin{tabular}{|c|c|c|c|}
\hline & & & Institucional \\
\hline Camaquã & 6 & $\begin{array}{c}6 \\
\text { Reunião }\end{array}$ & \\
\hline Ibicuí & 12 & $\begin{array}{c}2 \\
\text { Reunião, oficina }\end{array}$ & $\begin{array}{c}10 \\
\text { Monitoramento, água, unidade de } \\
\text { conservação, atividades do comitê, } \\
\text { parcerias de trabalho, balsa parada, } \\
\text { irrigação } \\
\end{array}$ \\
\hline Alto Jacuí & 23 & $\begin{array}{c}8 \\
\text { Curso, prêmio, } \\
\text { reunião, projeto, } \\
\text { participação em } \\
\text { evento }\end{array}$ & $\begin{array}{l}15 \\
\text { Relatório, enquadramento das } \\
\text { águas, estudo, propostas, orçamento } \\
\text { aprovado, metas futuras, audiência } \\
\text { pública, cedência equipamentos, } \\
\text { monitoramento, fiscalização, } \\
\text { cadastramento, açudes }\end{array}$ \\
\hline Pardo & 6 & $\begin{array}{c}3 \\
\text { Semana da água, } \\
\text { palestra, reunião }\end{array}$ & $\begin{array}{c}3 \\
\text { Visita técnica, parceria }\end{array}$ \\
\hline Passo Fundo & 18 & $\begin{array}{c}3 \\
\text { Assembleia, Agenda } \\
\text { 21, prêmios, reunião }\end{array}$ & $\begin{array}{l}15 \\
\text { Projeto, campanha, reciclagem, } \\
\text { relatório, limpeza do rio, } \\
\text { enquadramento das águas, audiência } \\
\text { pública, poluição por agrotóxicos }\end{array}$ \\
\hline Rio Negro & 7 & & $\begin{array}{c}7 \\
\text { Estudo água, projeto, mapa, sistema } \\
\text { informação, monitoramento }\end{array}$ \\
\hline Santa Maria & 6 & & $\begin{array}{l}6 \\
\text { Plano de bacia, portaria, barragens, } \\
\text { grupo de trabalho }\end{array}$ \\
\hline
\end{tabular}

Fonte: as autoras.

Como se observa, quem não privilegia o site ou o blog, utiliza prioritariamente o facebook. Cabe ressaltar que Tramandaí usa da estratégia de publicar notícias originalmente postadas em outros sites, além de postar várias notícias sobre o mesmo tema de fontes diferentes. A maioria refere-se a questões da bacia, com título e link, provenientes em geral de fontes midiáticas. O referido comitê, não produz notícias, mas funciona como um meio de acesso a um banco de dados sobre o tema aos internautas, o que demonstra preocupação com o dever de informar. Todavia, o uso indiscriminado desta sistemática resulta em inequívoca dificuldade de compreensão, além de sentir-se falta de uma contextualização das informações em relação ao local com notícias próprias. 
Quadro 4 - Temas das notícias publicadas no Facebook

\begin{tabular}{|c|c|c|c|}
\hline Comitê/Categoria & $\begin{array}{l}\text { Número } \\
\text { notícias }\end{array}$ & Categoria Eventos & Categoria Divulgação \\
\hline Taquari Antas & 7 & $\begin{array}{c}5 \\
\text { Reunião }\end{array}$ & $\begin{array}{c}2 \\
\text { Pesquisa, curso }\end{array}$ \\
\hline Sinos & 0 & & \\
\hline Tramandaí & 18 & $\begin{array}{c}8 \\
\text { Palestra, encontro } \\
\text { bacias, reunião, } \\
\text { assembleia }\end{array}$ & $\begin{array}{c}10 \\
\text { Lançamento de atlas, fotos, cursos, } \\
\text { inscrições projeto, privatização da água, } \\
\text { secas e inundações, usos da água }\end{array}$ \\
\hline Caí & 34 & $\begin{array}{c}10 \\
\text { Posse eleitos, } \\
\text { palestra, reuniões, } \\
\text { fóruns, celebração }\end{array}$ & $\begin{array}{c}24 \\
\text { Educação ambiental, espaço na mídia, } \\
\text { horários do comitê, mensagem de natal, } \\
\text { alerta, papel do comitê, estudo, inscrições, } \\
\text { membros, cursos, enchente, chuva, } \\
\text { bloqueio de rodovia, plano de saneamento }\end{array}$ \\
\hline Camaquã & 0 & & \\
\hline Ibicuí & 28 & $\begin{array}{c}12 \\
\text { Reunião, regata } \\
\text { ecológica, semana da } \\
\text { água, encontro de } \\
\text { comitês, fóruns }\end{array}$ & $\begin{array}{l}16 \\
\text { Balsa parada, rede de esgoto, plantio } \\
\text { direto, marco gaúcho das águas, cheia, } \\
\text { projeto, oficina, audiência pública, } \\
\text { imagens, telefones do comitê }\end{array}$ \\
\hline Alto Jacuí & 0 & & \\
\hline Pardo & 49 & $\begin{array}{c}24 \\
\text { Expedição, reunião, } \\
\text { encontro comitês, } \\
\text { palestra, evento } \\
\text { comitê, seminário }\end{array}$ & $\begin{array}{c}22 \\
\text { Divulgação de chamada plenária, } \\
\text { mensagem, instalação de rede telemétrica, } \\
\text { criação de comissão, eleições, imagens, } \\
\text { poesia, exposição de fotos, curso, } \\
\text { entrevista, projeto, gestão, comunicado }\end{array}$ \\
\hline Passo Fundo & 4 & $\begin{array}{c}1 \\
\text { Reunião }\end{array}$ & $\begin{array}{c}3 \\
\text { Foto, reciclagem }\end{array}$ \\
\hline Rio Negro & 0 & & \\
\hline Santa Maria & 56 & 42 & $\begin{array}{c}14 \\
\text { Documentos, preservação, dia mundial da } \\
\text { água, entrega de ofício, mensagem, água e } \\
\text { desenvolvimento, imagem, assinatura de } \\
\text { protocolo, compromissos do comitê em } \\
\text { Brasília, treinamento outorga, poesia, } \\
\text { plano de saneamento }\end{array}$ \\
\hline
\end{tabular}

Fonte: As autoras.

Dos 11 comitês, 6 publicaram alguma notícia sobre plano de bacia, enquadramento ou audiências públicas em 2013, sendo eles: Taquari-Antas, Sinos, Alto Jacuí, Passo Fundo, Santa Maria e Ibicuí.

De modo geral, os que usaram as mídias de internet o fizeram para comunicar eventos do comitê ou relacionados à questão da água, e divulgar ações de educação ambiental, estudos, projetos, problemas da água, monitoramentos realizados, cheias, legislações, mensagens institucionais e cursos. 
Quadro 5 - Soma de notícias publicadas no site/blog e Facebook

\begin{tabular}{lccc}
\hline \multicolumn{1}{c}{ Comitê/Categoria } & Total notícias & Categoria Eventos & Categoria Divulgação \\
\hline Taquari Antas & 26 & 12 & 14 \\
\hline Sinos & 19 & 7 & 40 \\
\hline Tramandaí & 55 & 15 & 25 \\
\hline Caí & 35 & 10 & 0 \\
\hline Camaquã & 6 & 6 & 26 \\
\hline Ibicuí & 40 & 14 & 28 \\
\hline Alto Jacuí & 23 & 8 & 18 \\
\hline Pardo & 55 & 27 & 7 \\
\hline Passo Fundo & 22 & 4 & 20 \\
\hline Rio Negro & 7 & 0 & $\mathbf{2 0 5}$ \\
\hline Santa Maria & 62 & 42 & $\mathbf{1 4 5}$ \\
\hline Total & $\mathbf{3 5 0}$ & & \\
\hline Fonte: As autoras & & & \\
\hline
\end{tabular}

Do total de notícias publicadas pelos 11 comitês, 145 referiram-se a eventos promovidos pelos próprios comitês ou por parceiros que atuam sobre o tema das águas. Outras 205 notícias focaram a divulgação de temas já referidos nos quadros 3 e 4.

Das 350 notícias publicadas pelos 11 comitês, 212 delas, ou seja, $66 \%$ do total foram midiatizadas por quatro comitês: Tramandaí, Ibicuí, Pardo e Santa Maria. Os outros 7 comitês juntos publicaram apenas um terço, o que mostra um desequilíbrio na quantidade de publicações realizadas entre os comitês.

Pode-se observar no Quadro 5 uma grande variação no uso destas mídias pelos diferentes comitês: o que menos publicou noticiou 6 vezes, enquanto que o que mais usou destas ferramentas de mídia publicou 62 notícias em 2013. Mesmo o que mais publicou, noticiou em média um fato por semana. $\mathrm{O}$ que demonstra o baixo uso das ferramentas de comunicação midiáticas pelos comitês de bacia do RS. É preciso considerar ainda que 14 deles não foram incluídos neste estudo porque não usam as mídias disponíveis na internet. Estes comitês podem, no entanto, estar fazendo uso das mídias tradicionais: rádio, jornal e televisão locais e regionais.

c) Imagens

Quanto à categoria das imagens, o Taquari Antas publica mais, mas foca na categoria Evento Interno, reuniões (22 do total de 29). Já o Sinos diversifica as imagens entre as categorias, enquanto o Tramandaí não produz informação, apenas repassa de outros sites. Rio Negro, Santa Maria, Camaquã e Caí publicam poucas imagens e dentro de apenas uma categoria. Os demais publicam poucas imagens e diversificam entre as categorias. 
O uso de fotografias por quem privilegia o site é mais diversificado. O maior uso de fotografias se relaciona a divulgação de eventos internos e externos (reuniões, palestras, ações ecológicas e de monitoramento) e ilustrações (institucionais e para divulgação de eventos).

Também a divulgação de imagens no Facebook por quem privilegia este meio recai predominantemente nas categorias evento interno (reuniões, fóruns, visitas, cursos e eleições) e ilustrações (mensagens, convites, campanhas, eventos, replicação de notícias publicadas em jornais).

Quadro 6 - Soma das imagens publicadas nas notícias do site e blog e Facebook

\begin{tabular}{|c|c|c|c|c|c|c|}
\hline Comitê/Categoria & $\begin{array}{l}\text { Evento } \\
\text { Interno }\end{array}$ & $\begin{array}{c}\text { Evento } \\
\text { Externo }\end{array}$ & Ilustração & $\begin{array}{l}\text { Situação } \\
\text { Ecológica }\end{array}$ & Institucional & $\begin{array}{l}\text { Total } \\
2013\end{array}$ \\
\hline Taquari Antas & 22 & 0 & 0 & 6 & 1 & 29 \\
\hline Sinos & 9 & 2 & 5 & 1 & 0 & 17 \\
\hline Tramandaí & 3 & 4 & 16 & 6 & 0 & 29 \\
\hline$\overline{\text { Caí }}$ & 4 & 6 & 9 & 14 & 0 & 33 \\
\hline Camaquã & 8 & 0 & 0 & 0 & 0 & 8 \\
\hline Ibicuí & 15 & 4 & 11 & 8 & 0 & 38 \\
\hline Alto Jacuí & 3 & 0 & 2 & 2 & 1 & 8 \\
\hline Pardo & 84 & 2 & 12 & 0 & 0 & 98 \\
\hline Passo Fundo & 5 & 2 & 3 & 2 & 0 & 12 \\
\hline Rio Negro & 0 & 0 & 0 & 5 & 0 & 5 \\
\hline Santa Maria & 33 & 0 & 17 & 0 & 1 & 51 \\
\hline Total & 186 & 20 & 75 & 44 & 3 & 328 \\
\hline
\end{tabular}

De modo geral os comitês não publicam fotografias institucionais nas mídias analisadas. O tipo de imagem mais publicada é de Eventos em ambientes internos: 56\%. Três comitês publicam majoritariamente este tipo de imagem: Pardo, seguido por Santa Maria e Taquari Antas. Em segundo lugar surgem as Ilustrações com 22,8\%, espécie de imagem bastante utilizada pelos comitês Santa Maria, Tramandaí, Pardo e Ibicuí. Em seguida surgem as imagens de Situações Ecológicas 13,4\%, pouco publicadas pelos comitês em geral, mas bastante utilizadas pelo comitê Caí, onde figura como a principal imagem publicada. 
Quadro 7 - Quantificação de notícias e imagens por comitê

\begin{tabular}{lcc}
\hline Comitê/Categoria & Total de notícias & $\begin{array}{c}\text { Total de imagens } \\
\mathbf{2 0 1 3}\end{array}$ \\
\hline Taquari Antas & 26 & 29 \\
\hline Sinos & 19 & 17 \\
\hline Tramandaí & 55 & 29 \\
\hline Caí & 35 & 33 \\
\hline Camaquã & 6 & 38 \\
\hline Ibicuí & 40 & 8 \\
\hline Alto Jacuí & 23 & 12 \\
\hline Pardo & 55 & 5 \\
\hline Passo Fundo & 22 & 51 \\
\hline Rio Negro & 7 & $\mathbf{3 2 8}$ \\
\hline Santa Maria & 62 & \\
\hline Total & $\mathbf{3 5 0}$ & \\
\hline Fonte: As autoras. & & 38 \\
\hline
\end{tabular}

As 350 notícias publicadas pelos 11 comitês foram acompanhadas por 328 imagens, o que dá uma imagem por notícia, em média. Verifica-se que esta média muda para Tramandaí, Alto Jacuí e Passo Fundo, que publicaram mais notícias (55, 23, 22 respectivamente) acompanhadas de menos imagens (29, 8, 12 respectivamente). Já o Comitê Pardo privilegiou o uso de imagens em relação à publicação de notícias (98 imagens em 55 notícias).

\subsection{Categoria Redes}

a) Uso e relacionamento nas redes sociais

Em relação ao Facebook, como já afirmado, apenas 7 usam esta ferramenta. Em 2013 suas postagens variaram de 4 (Passo Fundo) a 56 (Santa Maria), sendo que os dois comitês que mais postam (Santa Maria e Pardo), o fazem apenas uma vez por semana, em média. Caí e Ibicuí postam uma vez a cada duas semanas, em média. Tramandaí uma vez a cada três semanas. Passo Fundo e Taquari Antas postaram em média uma vez a cada dois ou três meses.

Os temas das postagens variam em cinco categorias: cheias e secas, divulgação de ações e eventos institucionais, dicas voltadas para educação ambiental, monitoramento das águas e gestão.

Quando da divulgação de reuniões, estas referem-se a reuniões ordinárias ou extraordinárias dos comitês, de ordem técnica, para definição de eleições, audiências públicas e para discutir plano de gestão da bacia. 
O relacionamento nas redes sociais entre os sete comitês que usam o Facebook é baixíssimo, com no máximo 9 curtidas. Os compartilhamentos variam de zero a quatro por notícia. Os comentários variam de zero a 1 por notícia.

b) Integração com outros órgãos

Os sites disponibilizavam links para outros órgãos. Quando o faziam os links mais recorrentes eram para Agência Nacional de Águas (ANA), Secretaria de Meio Ambiente do Rio Grande do Sul (SEMA), Fundação Estadual de Proteção Ambiental Henrique Luiz Roessler - RS (FEPAM) e Ministério do Meio Ambiente (MMA). Outros órgãos que tinham links no site dos comitês, mas com menos frequência eram: Comitês de Gerenciamento das Bacias Hidrográficas do Rio Passo Fundo (CBHPF), Prefeitura Municipal de Passo Fundo (PMPF), Associação dos Usuários do Perímetro de Irrigação do Arroio Duro (AUD), Programa Nacional de Habitação Rural (PNHR), Informação, Cidadania, Ambiente (ICA), Plano Diretor de Irrigação no Contexto dos Usos Múltiplos da Água para o Rio Grande do Sul (PIUMA/RS), Portal do Encontro Nacional de Comitês de Bacias Hidrográficas (ENCOB), Rede Brasil de Organismos de Bacias (REBOB), Universidade Federal do Pampa (UNIPAMPA), Associação dos Usuários da Água da Bacia Hidrográfica do Rio Santa Maria (AUSM), Universidade de Caxias do Sul (UCS), Universidade do Vale do Taquari (Univates), Comitês de Bacias Hidrográficas (CBH), Ação Nascente Maquiné (ONG ANAMA), Instituto Chico Mendes de Conservação da Biodiversidade (ICMBIO), Ministério Público do Estado do Rio Grande do Sul (MPRS), Refinaria Alberto Pasqualini (REFAP), Petróleo Brasileiro S.A (PETROBRAS), Fórum Nacional de Bacias Hidrográficas, Sistema Estadual de Recursos Hídricos (SNRH), Código Estadual de Meio Ambiente, Instituto Brasileiro do Meio Ambiente e dos Recursos Naturais Renováveis (IBAMA), legislação de recursos hídricos e o Pró-Guaíba (programa do Governo do Estado do Rio Grande do Sul para promover o desenvolvimento socioambiental da Região Hidrográfica do Guaíba). Também oferecem link para Facebook próprio.

Portanto, os órgãos legitimados pelos comitês para informação hídrica são predominantemente órgãos oficiais e relacionados aos comitês, seguidos pelas universidades, ONGs e empresas.

\section{Discussão dos resultados}

O papel atribuído aos Comitês de Bacias Hidrográficas por meio da legislação de águas pressupõe que estes assumam a condição de parlamentos das águas, assegurando assim que os processos de decisão sejam democráticos, o que, por consequência impõe o exercício do direito à informação, posto que, o incremento da participação está diretamente relacionado à transparência das suas ações. 
No entanto, os dados apresentados, em síntese, apontam que dos 25 comitês do RS, apenas 19 possuíam site, sendo a visibilidade considerada ótima em 10 deles. Quanto a atualização somente 4 tinham apresentado atualização no mês de coleta. Verificou-se que não atualizavam ou não dispunham de informações em nenhuma das duas ferramentas 16 dos 25 comitês. E 14 não mantinham publicações periódicas nas mídias disponibilizadas na internet. Dos 11 comitês, 6 publicaram alguma notícia sobre plano de bacia, enquadramento ou audiências públicas no período analisado. O uso das mídias de Internet caracterizou-se pela comunicação sobre eventos, divulgação de ações de educação ambiental, estudos, projetos, problemas da água, monitoramentos, cheias, legislações, mensagens institucionais e cursos. Portanto, demonstra-se que as mídias virtuais não estavam disseminadas entre os comitês e, também, entre aqueles que as utilizavam, seu uso não era estratégico.

Ainda, quem as usava, nem sempre as atualizava com frequência, de modo a informar à população e despertar interesse neste tema de cidadania. Havia também uma centralização das publicações em quatro comitês, pois das 350 notícias 212 (ou 66\%) foram publicadas por 11 deles e outros 7 comitês juntos publicaram apenas um terço do total. O relacionamento nas redes sociais entre os sete comitês que usavam o Facebook era baixíssimo. Evidencia-se, assim, que além de pouca informação midiatizada, gerava-se pouco diálogo.

Poma e Gravante (2013, p. 143) referem que não é possível uma gestão participativa da água "sem uma política democrática da comunicação, baseada no diálogo, na construção compartilhada da cidadania e no compromisso público". Nesse sentido asseveram que a obrigação legal de publicar e permitir o acesso ao público às informações não assegura, por si só, a participação. A informação deve ser permeada por processos de comunicação que se voltem as mudanças sociais mediante "la integración de los sistemas de información y comunicación públicos, así como los recursos tecnológicos y las culturas populares, en la acción y gestión comunitaria local socializando los recursos de expresión e identicación grupal y colectivos entre las redes sociales".

A análise das informações difundidas pelos comitês gaúchos por meio dos seus canais de comunicação da internet fez emergir elementos relacionados ao acesso, oferta de informação e uso das redes sociais que guiam esta discussão. Trata-se da relação das informações ofertadas com o direito à informação, do dever institucional de informar, da relevância das publicações, dos reflexos nos processos de cidadania e para a participação nos comitês.

Como visto anteriormente, a Lei 12.527 que trata do acesso à informação, impõe o dever de informar aos órgãos públicos da administração direta e indireta, - aqui incluídos, os Comitês de Bacias Hidrográficas, uma vez que, segundo seus Decretos de criação estes são compreendidos como órgãos de Estado - que envolve a produção de informação a partir das atividades por estes desenvolvidas, das quais quer se dar conhecimento a população. 
Neste sentido, vê-se que no âmbito do RS, somente 11 Comitês têm tentado assegurar o cumprimento deste direito, por meio dos espaços virtuais, visto que, 14 não utilizam a internet para difundir informações ou ainda deixam de atualizá-la.

Dos comitês que se utilizam dos sites e Facebook para informar, muitos se limitam a reproduzir informações fomentadas por outros órgãos de comunicação, como a mídia comercial, em detrimento daquelas por eles produzidas e relativas às atividades desenvolvidas, o que também contraria a proposta da lei.

A Lei também é clara ao privilegiar o repasse de determinadas informações, como referido no Art. $2^{\circ}$ da Lei 10.650, cabendo às administrações dos comitês tal cuidado, no sentido de não difundir apenas informações de caráter institucional ou, ainda, reproduzir matérias veiculadas pela mídia comercial. Isto, contudo, impõe uma necessária revisão das formas de gerir a informação pelos comitês, que demonstraram ser conservadoras e pouco sedutoras dos cidadãos para sua participação nos comitês.

Pode-se sustentar que, ao proporem tal dever aos órgãos públicos, tanto a Constituição Brasileira de 1988 como as leis de informação, objetivavam implementar uma forma de se ampliar a participação dos cidadãos nos processos decisórios, visto que, a participação política na esfera pública está condicionada à preparação dos cidadãos, o que, passa necessariamente pelo exercício do direito à informação.

Neste sentido, se o objetivo de informar é o de ampliar a participação, mais do que divulgar informações com caráter institucional (como agendas, endereços, contatos, datas de reuniões, regimentos, legislação e outros), cabe aos Comitês um novo olhar acerca do que divulgar, voltados para as reais necessidades da sociedade e para as demandas do local, permitindo uma identificação por parte do cidadão e, consequentemente, um maior envolvimento com a problemática hídrica.

Euler e Heldt (2018) em estudo relacionado aos processos de informação estabelecidos na Diretiva Quadro da Água, referiram que a simples previsão do direito a informação nos textos normativos, mesmo que considerada uma evolução normativa, não é capaz por si só de garantir o diálogo com as comunidades afetadas, haja vista que muitas vezes os textos denotam uma informação unidirecional, prevendo o simples compartilhamento desta.

A concretização do exercício do direito à informação requer a oferta de possibilidades aos cidadãos para a compreensão da complexidade das questões hídricas fundamentais, de modo que sintam-se ativamente empoderados (emancipados, capazes de permitir a superação da dominação política e a dependência social), para conquistar a posição de atores informados e participativos nos comitês, que tem como razão de ser, em última instância, a garantia de acesso universal à água própria para o consumo humano.

Como defende Gentilli (2012, p. 6) "a informação é uma prerrogativa para que o cidadão tenha plenas condições de fazer suas escolhas. Relaciona-se à liberdade de expressão. É a forma 
como se manifesta presentemente a liberdade de manifestação e de expressão no contexto do Estado de direito".

Compreendido como um direito, a informação não possui um fim em si mesmo, mas um propósito maior, relacionado a "capacidade de facilitar ao cidadão ao acesso aos demais direitos declarados", como é o caso do direito de acesso à água potável. Numa sociedade que se intitula democrática o alargamento da cidadania por meio do acesso a outros direitos não pode ser mera promessa (GENTILLI, 2012, p. 6).

Conforme informa o World Information Report da Organização das Nações Unidas para a Educação, a Ciência e a Cultura (UNESCO), "há uma grande diferença entre ter um direito e poder exercê-lo. Pessoas pouco informadas se vêm frequentemente privadas dos seus direitos porque lhes falta o poder para o seu exercício. O acesso à informação é um direito que temos, como o acesso à justiça, e deveria ser assegurado gratuitamente como outros serviços públicos" (ORGANIZAÇÃO DAS NAÇÕES UNIDAS PARA A EDUCAÇÃO, A CIÊNCIA E A CULTURA, 1997, p. 282).

Ao exercitar a prerrogativa imposta pela lei, os órgãos públicos contribuem para uma atuação mais ativa, retirando, por consequência, da tutela das forças de mercado a posição de formadores de opinião.

A realização de escolhas e o livre desenvolvimento da personalidade somente serão assegurados em uma comunidade com conhecimento dos planos, projetos, políticas e ações que possam "comprometer seus projetos de vida, ou uma pluralidade de projetos existenciais, culturais, sociais e economicamente diferenciados", sem esquecer da forte e estreita vinculação deste direito com os princípios da dignidade humana (art. $1^{\circ}$, III, da CF/1988) e da prevalência dos direitos humanos (art. $4^{\circ}$, II, da CF/1988), contemplados na ordem constitucional brasileira como preceitos fundamentais de todo cidadão (MAZZUOLI; AYALA, 2012, p. 297-328).

$\mathrm{O}$ dever de assegurar o direito à informação também envolve outras premissas. Entre estas, destaca-se a necessidade do emprego de uma linguagem e textos acessíveis ao grande público, evitando a linguagem técnica, a qual deve ser traduzida a ponto de permitir a compreensão dos cidadãos que se quer informar.

A Portaria Interministerial 140 de 16 de março de 2006 que disciplina a divulgação de dados e informações pelos órgãos e entidades da Administração Pública Federal, por meio da rede mundial de computadores - internet, pode contribuir com tais prerrogativas, em especial no que se refere aos resultados do presente estudo, pois conforme mencionado, o uso de uma linguagem simples e clara com o apoio de imagens não faz parte da dinâmica de divulgação da maioria dos Comitês do RS. Os artigos 16, 17, 18 e 20 da Portaria preveem que as informações devem ser apresentadas de forma simples e objetiva, com a utilização de recursos de navegação intuitiva a qualquer cidadão, sem requerer, conhecimentos específicos de informática. Acerca do conteúdo técnico a portaria menciona que este deve ser precedido, sempre que possível, de texto 
introdutório e, acompanhado por notas explicativas, na forma de dicas de tela e reforça ainda a necessidade de que as páginas contenham um glossário com as definições, em linguagem acessível ao cidadão, de todos os termos técnicos empregados na apresentação das informações (BRASIL, 2006).

Como refere Dowbor (2003, p. 2), a sociedade precisa de uma informação organizada que permita a ação informada do cidadão, da empresa, do funcionário público, da organização da sociedade civil, sob pena dela sucumbir a enxurrada de informações sensacionalistas e interessadas que mais desorientam do que informam.

Diante de um universo repleto de possibilidades que representa a internet, tornar atraentes e merecedores de atenção assuntos como os que permeiam as práticas diárias dos Comitês de Bacias talvez se constitua, na atualidade, num dos maiores desafios para construção da virtualidade da informação ambiental, afinal, conforme refere Castells (2009), o emprego das redes de comunicação horizontais para difusão de mensagens potencializa mudanças políticas e culturais, uma vez que tal mecanismo permite a produção autônoma de informação. $\mathrm{O}$ autor assinala o deslocamento do espaço público para o âmbito virtual, o qual, mesmo sendo maior e o mais interativo que se apresenta ao longo da história, está sendo muito disputado.

A potencialidade de transformação destes meios é desmerecida pelos comitês de bacias hidrográficas quando demonstram o padrão evidenciado nas análises. Justamente quando as mídias virtuais possibilitam a autonomia na gestão da informação. Castells (2009) propõe aos atores sociais que reafirmem o direito à autocomunicação de massas fazendo sua própria gestão da comunicação. Isto porque as pessoas formam suas ideias das coisas a partir da informação que lhes chega por meio das redes de comunicação, fonte da maioria dos cidadãos, diz.

O simples repasse de informações relacionadas à água, de forma desarticulada, descontextualizada e pouco aprofundada em sua complexidade não atende ao que está posto como dever dos comitês. Exemplo de como a informação pode contribuir para a gestão dos recursos hídricos é a presente crise hídrica enfrentada pelo estado de São Paulo. Os sistemas de racionamento foram organizados de última hora, o que fez com que muitas famílias ficassem sem água. Ocorre que a escassez estava anunciada, mas não propagada. Dados da Agência Nacional de Águas davam conta, ainda no início de 2014 que o balanço hídrico do sudeste brasileiro poderia vir a comprometer o acesso à água. O estado do RS também passa por tal ameaça. Em matéria publicada em jornal de grande circulação no estado, informando sobre estudo da Agência Nacional de Águas informou-se que o balanço hídrico do RS é o segundo pior do país (CIGANA, 2014).

Como os Comitês gaúchos têm trabalhado com esta informação? As discussões presentes em suas páginas de internet têm contribuído para um posicionamento reflexivo dos cidadãos? Como se definem as pautas a serem veiculadas pelos comitês nos espaços da internet? As 
informações estão conectadas com os demais órgãos? Que critérios tem orientado a construção da virtualidade da informação ambiental? Qual a distância que separa os comitês da sociedade?

Ainda quanto aos mecanismos de divulgação utilizados, tem-se que aqueles que adotam a rede social denominada Facebook, demonstram superficialidade no tratamento das questões, o que, contudo, pode ser uma característica de tal instrumento. No entanto, o uso de imagens e links possibilitam aprofundar a abordagem por meio do envio para fontes diversas, permitindo assim que o cidadão venha a se posicionar diante das notícias. Trata-se de uma ferramenta que se prolifera entre os diferentes perfis sociais.

No que tange ao emprego das redes sociais, faz-se necessário reconhecer que a possibilidade de qualquer cidadão interagir na página do Comitê na rede também é uma forma de democratização das mídias, pois permite ao cidadão posicionar-se como produtor de informação. No entanto, observou-se que o relacionamento é quase nulo no perfil do Facebook dos comitês.

Também se percebe, a partir das escolhas feitas pelos comitês investigados, que a opção pelo que informar segue a lógica do que os comitês consideram importante informar por uma necessidade endógena e não baseada na escuta da sociedade, o que repercute na ausência da população e de muitos representantes que tem lugar e deliberam nas reuniões dos comitês.

Neste sentido, a abertura dos canais de comunicação aos cidadãos, por meio de espaços para realização de comentários, participação online, contato com os membros, pode sugerir uma ampliação nos processos de acompanhamento da gestão e do andamento das políticas públicas mais eficientes e, sobretudo, participativa e inclusiva

Diante da demonstração da baixa utilização dos mecanismos de comunicação no ambiente virtual para oferta de informações, posto que, como fora visto, somente 11 Comitês cumprem com o estabelecido na legislação e de modo parcial, outros questionamentos vem à tona: Qual a legitimidade dos comitês para decidir sobre os recursos hídricos, quando estes se colocam como um espaço democrático e participativo, mas não democratizam informações de modo a atrair cidadão participativos e informados às suas reuniões? Como o uso não estratégico de mídias próprias repercute nas decisões tomadas? Trata-se de um descuido ou de uma ação estratégica para manter as decisões sobre usos da água nas mãos de poucos, muitas vezes perpetuando desigualdades de acesso e o comprometimento com os segmentos de mercado?

Estes e vários outros questionamentos restam sem respostas no momento em que se analisam as formas de informar no ambiente virtual utilizadas pelos Comitês no RS: A quem se pretende atingir informando como os dados apontaram? A informação veiculada, de caráter essencialmente institucional, permite efetivamente a ampliação da participação? O perfil da população que hoje acessa os canais virtuais de informação é condizente com o que é divulgado nestes espaços por parte dos comitês? Os diferentes perfis de público estão contemplados? O que move o uso das ferramentas de internet pelos comitês? Em que medida a concentração de informação se reflete em concentração de poder nos comitês? Como é realizada a gestão da 
informação no âmbito dos comitês? Os comitês estão cientes das premissas legais instituídas quanto à obrigação dos comitês de informar aos cidadãos? O que compreendem por informar? Como ofertar um olhar sistêmico por meio da oferta de informações para fazer a gestão das águas como é necessário para os Planos Nacionais de Recursos Hídricos?

Enfim, quando o estudo deixa tantas questões indica a necessidade de outros e também a percepção que o cenário investigado demonstra que a participação emancipada ainda se coloca como uma promessa para o futuro, haja vista que além da necessária superação das dificuldades relacionadas ao dever de informar, faz-se necessária uma adaptação destes meios que leve em consideração também diferenças culturais entre os receptores da informação. Somente a partir desta virada é que o país será capaz de contrapor as críticas acerca do sistema de informações, como aquelas apresentadas por Geraldes e Reis (2012) no sentido de que ao longo da história os órgãos públicos não conseguiram constituir um diálogo com toda sociedade quando do compartilhamento das informações.

É preciso levar em conta que este cenário aponta também uma realidade inegável: o Brasil ainda vive a necessidade de desencadeamento de políticas públicas voltadas para a concretização dos direitos fundamentais, em especial, os direitos sociais, para que, sanadas as necessidades básicas, os cidadãos possam exercer seu direito de participação, sem que sejam alvo da pressão de grupos de interesse organizados ou, ainda, da elite econômica e intelectual.

Em um contexto marcado pela disseminação da informação de forma desordenada e complexa, o acesso ao direito a informação marca o reingresso dos indivíduos e da coletividade no jogo político ambiental. Sarlet e Fensterseifer (2018, p. 437) reiteram a importância do acesso à informação ambiental para consolidação da democracia participativa ecológica e classificam tal prerrogativa como direito fundamental relevante para proteção ambiental prevista constitucionalmente. Como lembram os autores "somente o cidadão devidamente informado e consciente da realidade e da problemática ambiental é capaz de atuar de forma qualificada no processo político, ensejando a autonomia e a autodeterminação da sua condição político participativa".

\section{Notas finais}

As formas como os Comitês hoje se apresentam vão de encontro aos preceitos mais elementares de uma concepção de cidadania que seja contemporaneamente adequada. A ideia de ser o homem um ser social, com direitos e deveres, passa ao largo da realidade na discussão sobre uma temática que afeta a todos.

O momento é propício para a divulgação de informações, haja vista que os Comitês do RS encontram-se em plena elaboração dos chamados Planos de Bacia, os quais, têm como objetivo geral a compatibilização entre oferta e demanda de água, em quantidade e qualidade, 
para todos os pontos da bacia hidrográfica. As informações contidas nestes Planos são ferramentas de grande relevância para a formatação de políticas públicas relacionadas as águas e, portanto, não podem permanecer a margem da sociedade.

Enfim, diante do exposto, verifica-se que o papel dos Comitês deve ser ampliado em se tratando da implementação do direito à informação. Estes devem ter presente que o uso correto dos seus sítios na internet deve ser capaz de fomentar a participação responsável de seus integrantes, visando à construção de uma sociedade, não apenas para "mim ou para os meus", mas para todos, pois este é o compromisso histórico que vincula cada cidadão brasileiro, não só em relação aos seus pares, mas também em relação às gerações futuras.

A sociedade necessita de instâncias de retroalimentação permanentes, as quais passam necessariamente pela garantia de acesso à informação, pois o risco de práticas antidemocráticas é permanente, pelo exaurimento das forças mobilizadoras da participação popular, devido aos “autointeresses", ao egoísmo e ao individualismo, que, por ser dos humanos, perpassam a gestão também dos comitês.

Entre tantos, este é mais um desafio que se impõe a presente geração, o qual apenas poderá ser eficazmente enfrentado se for possível dar passos consistentes no sentido de reconhecer no outro alguém que, mesmo diferente, é igual àquele que está a olhar, e não um estranho do qual é preciso se proteger. Uma vez superado isso, cada cidadão torna-se um zeloso protetor da água como bem comum, não só porque sem este bem sua vida torna-se inviável, mas também porque sua tutela the foi confiada por todos os demais, inclusive por aqueles que ainda não deram os primeiros passos na mais fantástica experiência, que é a existência humana.

\section{REFERÊNCIAS}

BRASIL. Controladoria-Geral da União. Portaria Interministerial $\mathbf{n}^{\circ}$ 140, de 16 de março de 2006. Disciplina a divulgação de dados e informações pelos órgãos e entidades da Administração Pública Federal, por meio da rede mundial de computadores - internet, e dá outras providências. Brasília: CGU, 2006. Disponível em: http://www.cgu.gov.br/sobre/legislacao/arquivos/portarias/portaria_cgu-mpog_140_2006.pdf,. Acesso em: 19 jul. 2019.

BRASIL. Lei no 10.650, de 16 de abril de 2003. Dispõe sobre o acesso público aos dados e informações existentes nos órgãos e entidades integrantes do Sisnama. Brasília, DF: Presidência da República, [2003]. Disponível em: http://www.planalto.gov.br/ccivil_03/LEIS/2003/L10.650.htm. Acesso em: 19 jul. 2019.

BRASIL. Lei $\mathbf{n}^{0}$ 12.527, de 18 de novembro de 2011. Dispõe sobre o acesso a informações públicas. Brasília, DF: Presidência da República, [2001]. Disponível em: http://www.planalto.gov.br/ccivil_03/_ato2011-2014/2011/lei/112527.htm. Acesso em: 17 jul. 2019.

CASTELLS, Manuel. Comunicación y poder. Madrid: Alianza Editorial, 2009. 
CAVALCANTI, Joyce Mariella Medeiros; DAMASCENO, Larissa Mayara da Silva; SOUZA NETO, Manoel Veras de. Observância da lei de acesso à informação pelas autarquias federais do Brasil. Perspectivas em Ciência da Informação, Belo Horizonte, v. 18, n. 4, p. 112-126, out./dez. 2013.

CIGANA, Caio. Estado tem o segundo pior desequilíbrio entre oferta e consumo de água no país. Zero Hora, Porto Alegre, 30 ago. 2014. Disponível em:

http://zh.clicrbs.com.br/rs/noticias/noticia/2014/08/estado-tem-o-segundo-pior-desequilibrioentre-oferta-e-consumo-de-agua-do-pais-4587208.html. Acesso em: 19 jul. 2019.

COMISSÃO ECONÓMICA DAS NAÇÕES UNIDAS PARA A EUROPA. Convenção sobre o acesso à informação, a participação do público no processo de tomada de decisões e o acesso à justiça no domínio do ambiente. Aarhus: UNECE, 2003. Disponível em:

http://www.unece.org/fileadmin/DAM/env/pp/EU\%20texts/conventioninportogese.pdf. Acesso em: Acesso em: 19 jul. 2019.

DOWBOR, Ladislau. Informação para cidadania e o desenvolvimento sustentável.

Transparência Brasil, São Paulo, 8 abr. 2003. Disponível em:

http://www.transparencia.org.br/docs/ladis2003.pdf. Acesso em: 19 jul. 2019.

EULER, Johannes; HELDT, Sonja. From information to participation and self-organization: Visions for European river basin management. Science of the Total Environment, v. 621, p. 905-914, 2018. Disponível em:

https://www.sciencedirect.com/science/article/pii/S0048969717331303. Acesso em: 23 maio 2018.

GENTILLI, Davi Lopes. Direito à informação e direito à comunicação: o percurso do jornalismo na constituição da cidadania. In: CONGRESSO BRASILEIRO DE CIÊNCIAS DA COMUNICAÇÃO - INTERCOM, 35. 2012, Fortaleza. Anais [...]. Fortaleza: Universidade de Fortaleza, 2012. Disponível em:

http://www.intercom.org.br/papers/nacionais/2012/resumos/R7-0814-1.pdf. Acesso em: 19 jul. 2019.

GERALDES, Elen; REIS, Lígia Maria. Da cultura da opacidade à cultura da transparência: apontamentos sobre a Lei do Acesso à Informação Pública. In: CONGRESSO BRASILEIRO DE CIÊNCIAS DA COMUNICAÇÃO - INTERCOM, 35. 2012, Fortaleza. Anais [...]. Fortaleza: Universidade de Fortaleza, 2012. Disponível em:

http://www.intercom.org.br/papers/nacionais/2012/resumos/R7-2167-1.pdf. Acesso em: 19 jul. 2019.

MAZZUOLI, Valerio de Oliveira; AYALA, Patryck de Araújo. Cooperação internacional para a preservação do meio ambiente: o direito brasileiro e a Convenção de Aarhus. Revista Direito GV, São Paulo, v. 8, n. 1, p. 297-328, jan./jun. 2012. Disponível em: http://www.scielo.br/scielo.php?script=sci_arttext\&pid=S180824322012000100012\&lng=pt\&nrm=iso\&tlng=en. Acesso em: 19 jul. 2019.

MORAES, R. Mergulhos Discursivos: análise textual qualitativa entendida como processo integrado de aprender, comunicar e interferir em discursos. In: GALIAZZI, M. do C.; FREITAS, J. V. de. (org.). Metodologias emergentes de pesquisa em educação ambiental. 2. ed. Ijuí: Ed. Unijuí, 2007.

ORGANIZAÇÃO DAS NAÇÕES UNIDAS. Declaração do Rio de Janeiro. Estudos Avançados, São Paulo, v. 6, n. 15, p. 153-159, 1992. Disponível em: http://www.scielo.br/scielo.php?script=sci_arttext\&pid=S0103$40141992000200013 \& \operatorname{lng}=$ en\&nrm=isom. Acesso em: 19 jul. 2019. 


\section{ORGANIZAÇÃO DAS NAÇÕES UNIDAS PARA A EDUCAÇÃO, A CIÊNCIA E A} CULTURA. World Information. Paris: UNESCO, 1997.

POMA, Alice; GRAVANTE, Tommaso. Participación ciudadana y políticas públicas. Pensar la gestión participativa del agua desde un enfoque comunicativo. Revista Jurídica de los derechos sociales - Lex Social, v.3 n.1, p.141-145, 2013.

SARLET, Ingo Wolfgang; FENSTERSEIFER, Tiago. Direitos ambientais procedimentais: acesso à informação, a participação pública na tomada de decisão e acesso à justiça em matéria ambiental. Revista Novos Estudos Jurídicos - Eletrônica, Itajaí, v. 23, n. 2, maio/ago. 2018.

Artigo recebido em: 2019-04-17

Artigo reapresentado em: 2019-06-26

Artigo aceito para publicação em: 2019-08-26 